\title{
Investigations of the Inhibition of Aluminum Corrosion in 1 M NaOH Solution by Lupinus varius $l$. Extract
}

\author{
Muna K. Irshedat, ${ }^{a, *}$ Eyad M. Nawafleh, ${ }^{a}$ Tareq T. Bataineh, ${ }^{a}$ \\ Riyadh Muhaidat, ${ }^{b}$ Mahmoud A. Al-Qudah $^{a}$ and Ahmed A. Alomary ${ }^{a}$ \\ ${ }^{a}$ Department of Chemistry, Faculty of Science, Yarmouk University, Irbid, Jordan \\ ${ }^{b}$ Department of Biology, Faculty of Science, Yarmouk University, Irbid, Jordan
}

Received 1 August 2012; accepted 15 January 2013

\begin{abstract}
The effect of the extract of Lupinus varius $l$. on corrosion of $\mathrm{Al}$ in $1 \mathrm{M} \mathrm{NaOH}$ solution using the weight loss technique was investigated. Lupinus varius $l$. extract inhibited the corrosion of $\mathrm{Al}$ in $1 \mathrm{M} \mathrm{NaOH}$ solution and the inhibition efficiency increased with increasing the concentration of the extract and decreased with increasing temperature. The adsorption of the inhibitor molecules on $\mathrm{Al}$ surface was in accordance with Langmuir and Temkin adsorption isotherms. A first-order kinetic relationship with respect to $\mathrm{Al}$ was obtained with and without the extract from the kinetics treatment of the data.
\end{abstract}

Keywords: aluminum, Lupinus varius l, inhibition efficiency, basic corrosion, weight loss technique.

\section{Introduction}

Several previous studies showed that naturally occurring substances of plant origin are successfully used as inhibitors of corrosion [1-7]. Previously, the corrosion of $\mathrm{Al}$ in alkaline solution has been investigated in the presence of organic and inorganic compounds [6-11], and in the presence of some plants extract, such as Gum Arabic [12], Pachylobus edulis and Raphia hookeri [13]. This work aims to studying the effect of Lupinus varius $l$. extract on the corrosion of $\mathrm{Al}$ in alkaline solution. Lupinus varius $l$. belongs to the family of Leguminosae. L. varius L. ssp. orientalis Franco et Silva (=Lupinusdigitatus Forssk, Lupinus pilosus L., Lupinus hispanicus and Lupinusmicroanthus) is an annual herb, growing in the Mediterranean, North Africa, South Europe, West

\footnotetext{
* Corresponding author. E-mail address: rshaidatm@yahoo.com
} 
Syria, and Palestine region [14,15]. Previous investigations of this species revealed the presence of several quinolizidine as well as dipiperidine alkaloids $[16,17]$. It has been shown that the inhibitory action of some plants solution extract is due to the presence of tannin, organic acids, amino acids, alkaloids and pigments in their chemical constiutions [18]. Alkaloids such as papaverine, strychnine, quinine and nicotine, were studied as corrosion inhibitors in acidic medium [5]. It has been shown that the inhibitive effect of the extract of some plants is due to the adsorption of molecules of phytochemicals present in the plant on the surface of the metal [19-21]; theses extract protect the metal surface and thus do not permit the corrosion process to take place.

Weight loss measurement was used to calculate the inhibition efficiency of the $L$. varius $l$. extract. The effect of temperature on the corrosion reaction rate in free and inhibited basic solutions was also investigated.

\section{Experimental}

The weight loss measurements were carried out in a test tube placed in a thermostat water bath. The solution volume was $10 \mathrm{~mL}$. Test specimens of $99.96 \%$ aluminium foil (length $=2 \mathrm{~cm}$, width $=1 \mathrm{~cm}$, thickness $=0.03 \mathrm{~cm}$ ), were degreased in acetone, chemically polished for $30 \mathrm{~s}$ in a solution containing $85 \%$ conc. $\mathrm{H}_{3} \mathrm{PO}_{4}$ and $15 \%$ conc. $\mathrm{HNO}_{3}$ at $85^{\circ} \mathrm{C}$, rinsed well in deionized water, etched for $20 \mathrm{~s}$ in a solution containing $40 \mathrm{gL}^{-1}$ sodium hydroxide at $40{ }^{\circ} \mathrm{C}$, rinsed again and immersed for $20 \mathrm{~s}$ in $1: 1 \mathrm{v} / \mathrm{v} \mathrm{HNO}_{3}$ at room temperature. After rinsing in deionized water and drying in a stream of air at room temperature, the specimens were kept in a desiccator.

\section{Inhibitor material}

A stock solution of the inhibitor material was prepared by refluxing $15.0 \mathrm{~g}$ of dry L.varius $l$. Powder with $250 \mathrm{~mL}$ of $1 \mathrm{M} \mathrm{NaOH}$ for 3 hours. The refluxed solution was allowed to stand overnight and filtered through ordinary filter paper. From this solution, different concentrations of inhibitor solutions ranging from 20 to $100 \%$ were diluted.

\section{Weight loss method}

Pre-weighed aluminium specimens (in triplicate) were suspended for 1 hour in 1 $\mathrm{M} \mathrm{NaOH}$ with and without the inhibitor in different volume ranging from 2 to 10 $\mathrm{mL}$ of extract. After the specified time, the coupons were removed from test solution, thoroughly washed with acetone solution and deionised water, dried well and then reweighed.

\section{Results and discussion}

The weight loss recorded to the nearest $0.0001 \mathrm{~g}$. The weight loss of the metal in the corrosive solution is given by equation 1 .

$$
\Delta \mathrm{W}=\mathrm{W}_{\mathrm{B}}-\mathrm{W}_{\mathrm{A}}
$$


where $\mathrm{W}_{\mathrm{B}}$ and $\mathrm{W}_{\mathrm{A}}$ are the weights of metal before and after exposure to the corrosive solution, respectively.

Fig. 1 shows the variation of the weight loss $(\mathrm{mg})$ of $\mathrm{Al}$ due to corrosion with the immersion time in $1 \mathrm{M} \mathrm{NaOH}$ solution of various concentrations of L. varius $l$. extract at $25^{\circ} \mathrm{C}$. The rate of reaction of $\mathrm{Al} 1 \mathrm{M} \mathrm{NaOH}$ decreases with time.

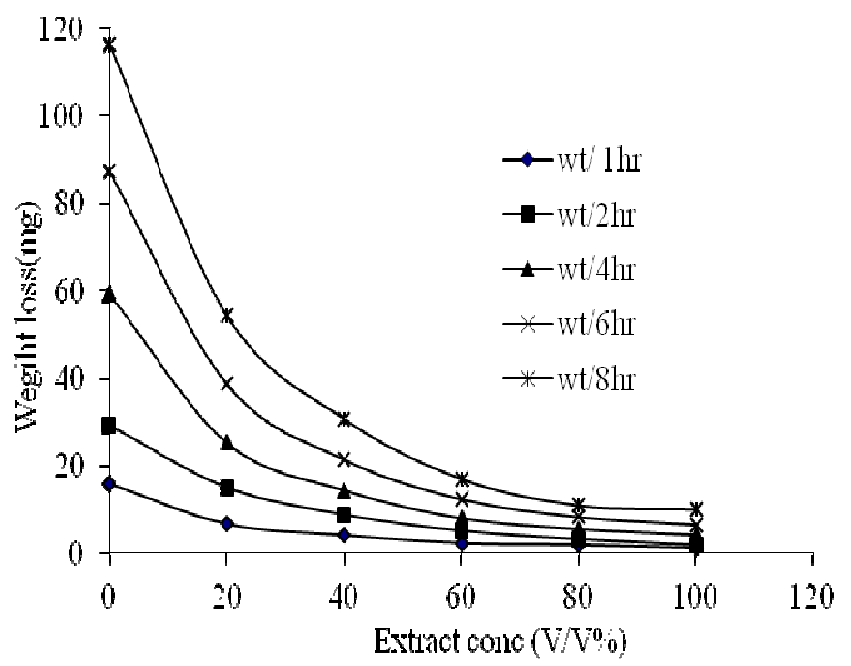

Figure 1. Weight loss variation of aluminum coupon versus L. varius $l$. extracts concentration in $1 \mathrm{M} \mathrm{NaOH}$ at $25^{\circ} \mathrm{C}$ at different immersion periods.

Weight loss of aluminum was determined, at various time intervals, in the absence and presence of different concentrations of $L$. varius $l$. extract. The curves in Fig. 1 show that the weight loss values (mg) of $\mathrm{Al}$ in $1 \mathrm{M} \mathrm{NaOH}$ solution containing $L$. varius $l$. extract decreased as the concentration of the inhibitors increased, i.e., the corrosion inhibition strengthened with the increase of the surfactant concentration. This trend, it may result from the fact that adsorption amount and the coverage of surfactants on the Al surface increase with the increase of the concentration, thus the Al surface is efficiently separated from the medium [12].

The weight loss curves of the Al with the addition of the inhibitors in different concentrations at various temperatures in $1 \mathrm{M} \mathrm{NaOH}$ are shown in Fig. 2. The effect of temperature on the corrosion of $\mathrm{Al}$ in $1 \mathrm{M} \mathrm{NaOH}$ over the temperature range of $\left(25-50{ }^{\circ} \mathrm{C}\right)$ in the absence and presence of different concentrations of the $L$ varius $l$. extract has been studied. The weight loss is found to increase with increasing temperature.

The percentage inhibition efficiency $(\% \mathrm{I})$ and the degree of surface coverage $(\theta)$ of the investigated $L$. varius $l$. extract were computed from the following equations:

$$
\begin{aligned}
& \% \mathrm{I}=\left[1-\left(\Delta \mathrm{W}_{\text {inh }} / \Delta \mathrm{W}_{\text {free }}\right)\right] \times 100 \\
& \theta=\left[1-\left(\Delta \mathrm{W}_{\text {inh }} / \Delta \mathrm{W}_{\text {free }}\right)\right]
\end{aligned}
$$

where $\Delta \mathrm{W}_{\text {free }}$ and $\Delta \mathrm{W}_{\text {inh }}$ are weight losses of metal in the absence and presence of inhibitor, respectively. 


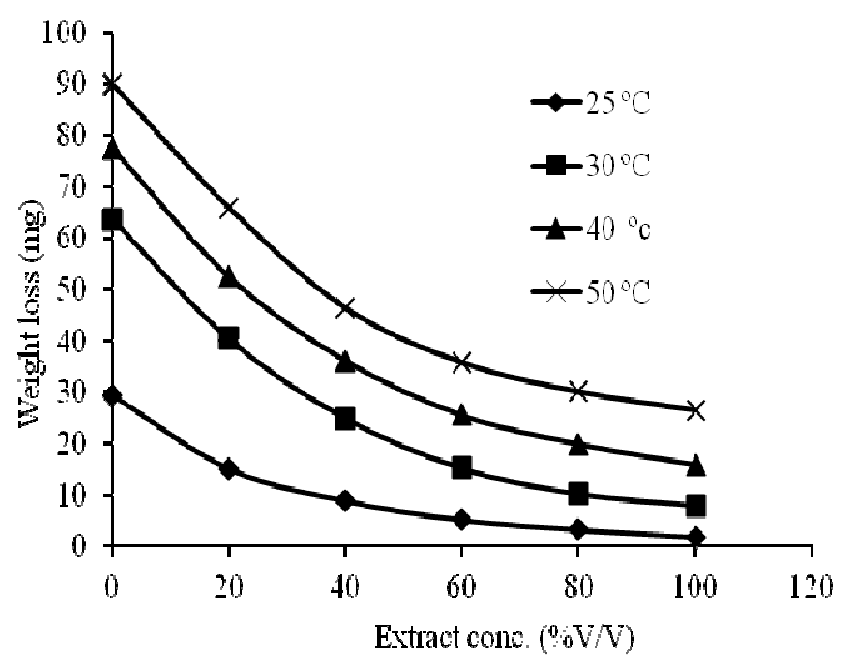

Figure 2. The weight loss curves of aluminum due to corrosion in $1 \mathrm{M} \mathrm{NaOH}$ in the presence of $L$. varius $l$. extract at various temperatures.

Table 1 shows the percentage inhibition efficiency of the inhibitors at various concentrations in $1 \mathrm{M} \mathrm{NaOH}$ for $60 \mathrm{~min}$ immersion period at different temperatures $\left(25-50{ }^{\circ} \mathrm{C}\right)$. The results showed that inhibition efficiency increased as the concentration of inhibitor increases from $20 \%$ to $100 \%$ of the extract used (Fig. 3). The maximum inhibition efficiency was observed at $25^{\circ} \mathrm{C}$ for $100 \%$ of extract, probably due to an increase in the metal surface area covered by the exudates. From Table 1, it is seen that inhibition efficiency of $L$. varius $l$. extract decreases with increase in temperature. Decrease in inhibition efficiency with increase in temperature is suggestive of physical adsorption mechanism.

Table 1. Inhibition efficiency of $L$. varius $l$. extract on aluminum in $1 \mathrm{M} \mathrm{NaOH}$ for 60 min immersion period at different temperatures.

\begin{tabular}{|c|c|c|c|c|}
\hline Extract conc. $(\% \mathrm{~V} / \mathrm{V})$ & $\%$ I at $25^{\circ} \mathrm{C}$ & $\%$ I at $30^{\circ} \mathrm{C}$ & $\%$ I at $40{ }^{\circ} \mathrm{C}$ & $\%$ I at $50^{\circ} \mathrm{C}$ \\
\hline 20 & 48.63 & 36.57 & 32.56 & 26.69 \\
\hline 40 & 69.95 & 60.89 & 53.37 & 48.43 \\
\hline 60 & 82.51 & 76.16 & 67.06 & 60.2 \\
\hline 80 & 89.04 & 83.91 & 74.3 & 66.52 \\
\hline 100 & 93.73 & 87.52 & 79.47 & 70.3 \\
\hline
\end{tabular}

The inhibitive effect of the L. varius $l$. extract could be attributed to the presence of some phytochemical constituents in the extract. Previous studies have shown that the $L$. varius $l$. extract contains alkaloids, tannin, oligosaccharides, polysaccharides and glucoproteins as part of its phytochemical composition [2023]. The presence of volatile monoterpenes and related oxygenated sesquiterpenes has been reported [24]. These compounds contain oxygen and nitrogen atoms which are the centers of adsorption.

Therefore it could be assumed that the extract gums establish their inhibitive action via adsorption of these phytochemical component molecules on the metal 
surface. This adsorption process creates a barrier between the metal and the corrosive medium leading to inhibition of corrosion. Consequently, inhibition efficiency increases as the metal surface area covered by the adsorbed molecules increases, the later is in turn increased as the extract concentration increases.

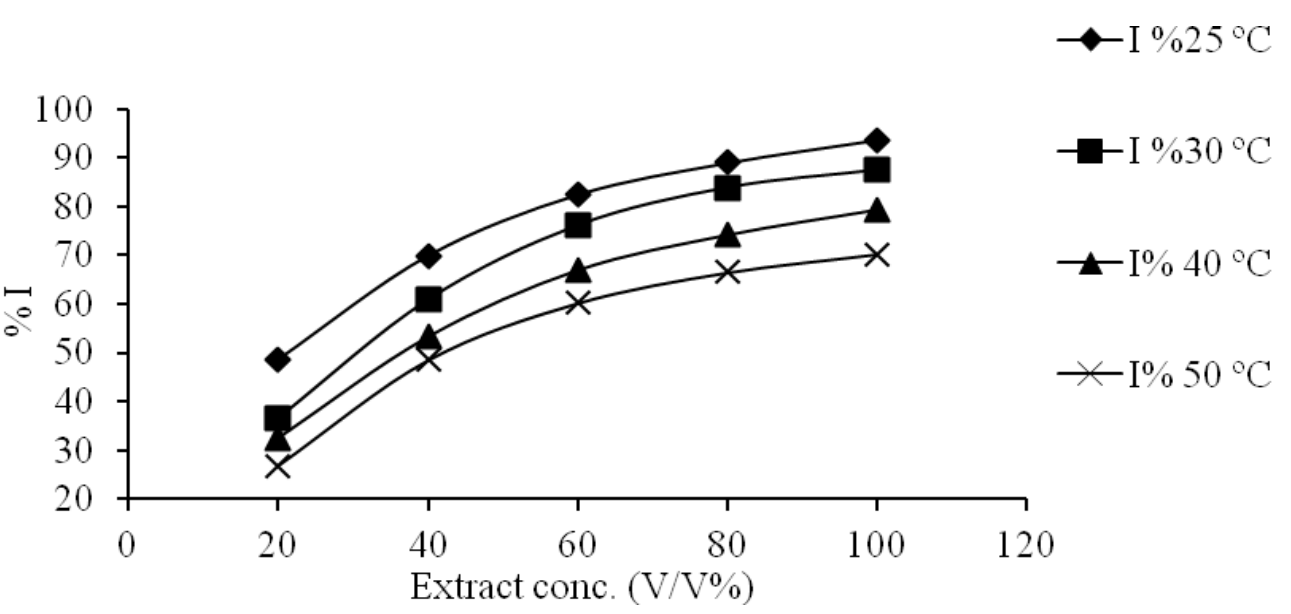

Figure 3. Inhibition efficiency of $L$. varius $l$. extract on aluminum in $1 \mathrm{M} \mathrm{NaOH}$ for 60 min immersion period at different temperatures.

\section{Effect of temperature and activation parameters of inhibition process}

The corrosion rate of $\mathrm{Al}$ is determined by using the relation:

$$
\mathrm{R}_{\text {corr }}=\Delta \mathrm{W} / \mathrm{A} \cdot \mathrm{t}
$$

where $\Delta \mathrm{W}$ is the mass loss, $\mathrm{A}$ the area and $\mathrm{t}$ the immersion period. The plot of logarithm of the corrosion rate versus the reciprocal of absolute temperature gives straight lines according to Arrhenius equation, Fig. 4:

$$
\log \mathrm{R}_{\text {corr }}=\mathrm{A}-\mathrm{Ea} / 2.303 \mathrm{RT}
$$

where $\mathrm{R}$ is the corrosion rate, $\mathrm{A}$ is the constant frequency factor and $\mathrm{Ea}$ is the apparent activation energy. The values of Ea were calculated and found to be 31.24 and $67.98 \mathrm{~kJ} / \mathrm{mol}$ for corrosion reactions in free and inhibited extract, respectively (Table 2). It is clear that, the activation energy increases in presence of $L$. varius $l$. extract and consequently the rate of corrosion reaction is decreased.

An alternative formulation of the Arrhenius equation is the transition state equation [25]:

$$
\mathrm{R}_{\text {corr. }}=\mathrm{RT} / \mathrm{Nh} \exp ^{(\Delta \mathrm{S} / \mathrm{R})} \exp ^{\left(-\Delta \mathrm{H}^{*} / \mathrm{RT}\right)}
$$

where $\mathrm{h}$ is Planck's constant, $\mathrm{N}$ is Avogadro's number, $\Delta \mathrm{S} *$ is the entropy of activation and $\Delta \mathrm{H}^{*}$ is the enthalpy of activation. 
Fig. 5 shows a plot of $\log ($ Rate/T) against (1/T). Straight lines are obtained with a slope of $\left(-\Delta \mathrm{H}^{*} / 2.303 \mathrm{R}\right)$ and an intercept of $\left(\log \mathrm{R} / \mathrm{Nh}+\Delta \mathrm{S}^{*} / 2.303 \mathrm{R}\right)$ from which the values of $\Delta \mathrm{H}^{*}$ and $\Delta \mathrm{S}^{*}$ are calculated and listed in Table 2 . The values of $\Delta \mathrm{H}^{*}$ are presented in Table 2. Enthalpy of activation of absolute values lower than $41.86 \mathrm{kJmol}^{-1}$ indicates physical adsorption, and values approaching 100 $\mathrm{kJmol}^{-1}$ indicate chemical adsorption [25]. In this study, the values of $\Delta \mathrm{H}^{*}$ are lower than $41.86 \mathrm{kJmol}^{-1}$ confirming physical adsorption. The values of $\Delta \mathrm{S}^{*}$ in the presence and absence of the inhibitors are negative. This implies that the activation complex is the rate determining step representing association rather than dissociation, indicating that a decrease in disorder takes place on going from reactant to the activated complex [20].

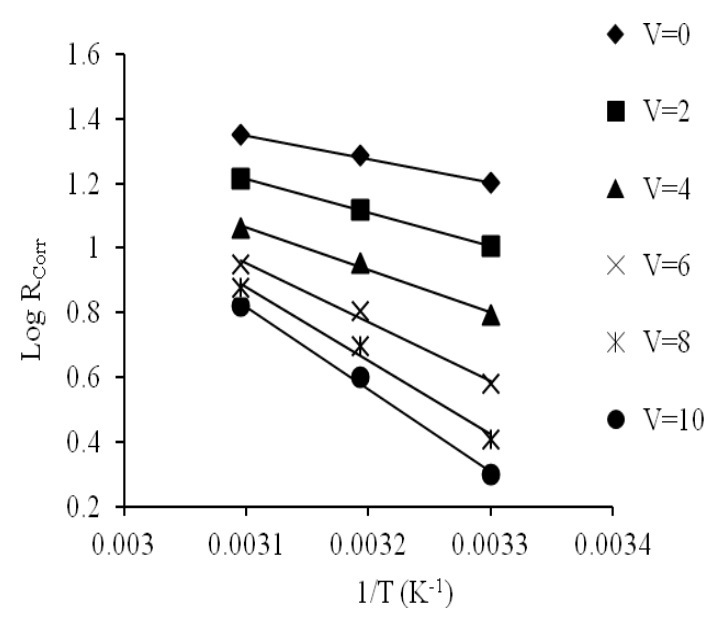

Figure 4. Arrhenius plot for aluminum dissolution in $1 \mathrm{M} \mathrm{NaOH}$ in the absence and presence of $L$. varius $l$. extract.

Table 2. Activation parameters of the dissolution of $\mathrm{Al}$ in $1 \mathrm{M} \mathrm{NaOH}$ in the absence and presence of $L$. varius $l$. extract.

\begin{tabular}{|c|c|c|c|}
\hline $\begin{array}{c}\text { Extract conc. } \\
(\boldsymbol{\%} \mathbf{V} / \mathbf{V})\end{array}$ & $\begin{array}{c}\Delta \mathbf{E} \\
(\mathbf{k J} / \mathbf{m o l})\end{array}$ & $\begin{array}{c}\Delta \mathbf{H}^{*} \\
(\mathbf{k J} / \mathbf{m o l})\end{array}$ & $\begin{array}{c}\Delta \mathbf{S}^{*} \\
(\mathbf{J} / \mathbf{m o l} . \mathbf{K})\end{array}$ \\
\hline 0 & 31.24 & 11.25 & -184.90 \\
\hline 20 & 41.40 & 17.16 & -169.20 \\
\hline 40 & 47.56 & 22.59 & -155.23 \\
\hline 60 & 57.07 & 32.14 & -127.70 \\
\hline 80 & 66.88 & 41.19 & -101.09 \\
\hline 100 & 67.98 & 46.23 & -89.65 \\
\hline
\end{tabular}

\section{Adsorption studies}

The values of $\mathrm{Q}_{\mathrm{ads}}$ on aluminum specimen in the presence of the inhibitor is arrived by the following equation (7)

$$
\mathrm{Q}_{\mathrm{ads}}=2.303 \mathrm{R}\left[\log \left(\theta_{2} / 1-\theta_{2}\right)-\log \left(\theta_{1} / 1-\theta_{1}\right)\right] \times\left(\mathrm{T}_{2} \mathrm{~T}_{1} / \mathrm{T}_{2}-\mathrm{T}_{1}\right)
$$

where $\mathrm{R}$ is the gas constant, $\theta_{1}$ and $\theta_{2}$ are the degree of surface coverage at temperatures $T_{1}$ and $T_{2}$, respectively. 
The calculated $\mathrm{Q}_{\mathrm{ads}}$ values are ranged from -58.84 to $-113.80 \mathrm{~kJ} / \mathrm{mol}$. This negative value indicates that the adsorption of $L$. varius $l$. extract on the surface of Al metal is exothermic [15].

$1 / \mathrm{T}\left(\mathrm{K}^{-1}\right)$

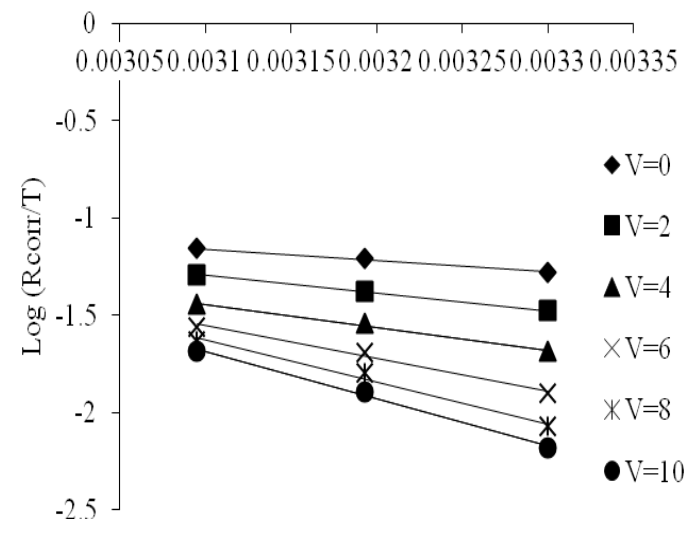

Figure 5. $\log$ (Rcorr./T) vs. $1 / \mathrm{T}$ for $\mathrm{Al}$ coupon in $1 \mathrm{M} \mathrm{NaOH}$ in the absence and presence of $L$. varius $l$. extract.

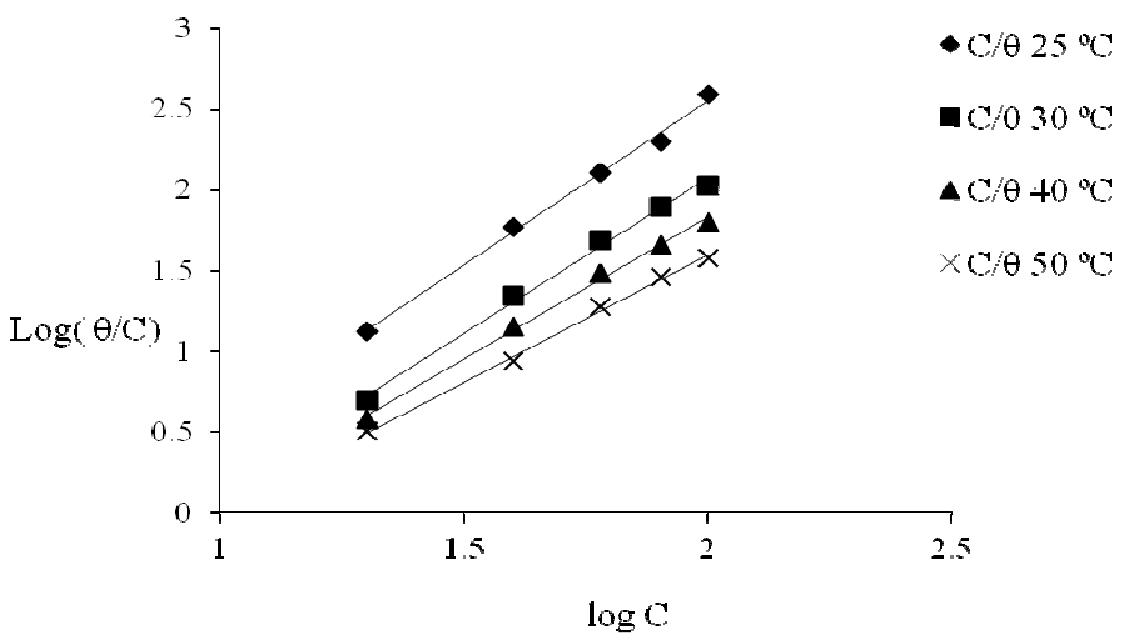

Figure 6. Langmuir adsorption model on aluminum surface of L. varius $l$. extract in 1 $\mathrm{M} \mathrm{NaOH}$ solution for 1 hour at different temperatures.

Fig. 6 also confirms that the inhibition process is due to adsorption of the active organic compounds on the metal surface. This is because a straight line is obtained when $\log (\mathrm{C} / \theta)$ is plotted against $\log C$ and the linear correlation coefficient of the fitted data is very close to 1 . This indicates that the adsorption of L. varius $l$. extract molecules obeys the Langmuir adsorption model $[10,18]$ expressed as

$$
\log (\mathrm{C} / \theta)=\log \mathrm{C}-\log \mathrm{K}
$$


where $\mathrm{C}$ is the inhibitor concentration and $\mathrm{K}$ is the equilibrium constant for the adsorption/desorption process of the inhibitor molecules on the metal surface. The inhibitor also obeys Temkin adsorption isotherm which is represented in Fig. 7, equation 9. Values of adsorption parameters deduced from the plots are recorded on Table 3.

$$
\operatorname{Exp}^{(-2 \mathrm{a} \theta)}=\mathrm{KC}
$$

The relationship between the equilibrium constant, $\mathrm{K}$, of adsorption and the free energy of adsorption, $\Delta \mathrm{G}_{\mathrm{ads}}$, is given by the following expression $[3,16]$

$$
\Delta \mathrm{G}_{\mathrm{ads}}=-2.303 \mathrm{RT} \log (55.5 \mathrm{~K})
$$

Values of free energy of adsorption calculated from equation (10) using $\mathrm{K}$ values obtained from the Langmuir adsorption and Temkin adsorption isotherm are presented in Table 2 . The values are negative and less than -40 $\mathrm{kJmol}^{-1}$. This implies that the adsorption of the inhibitor on aluminum surface is spontaneous and confirms physical adsorption mechanism [16].

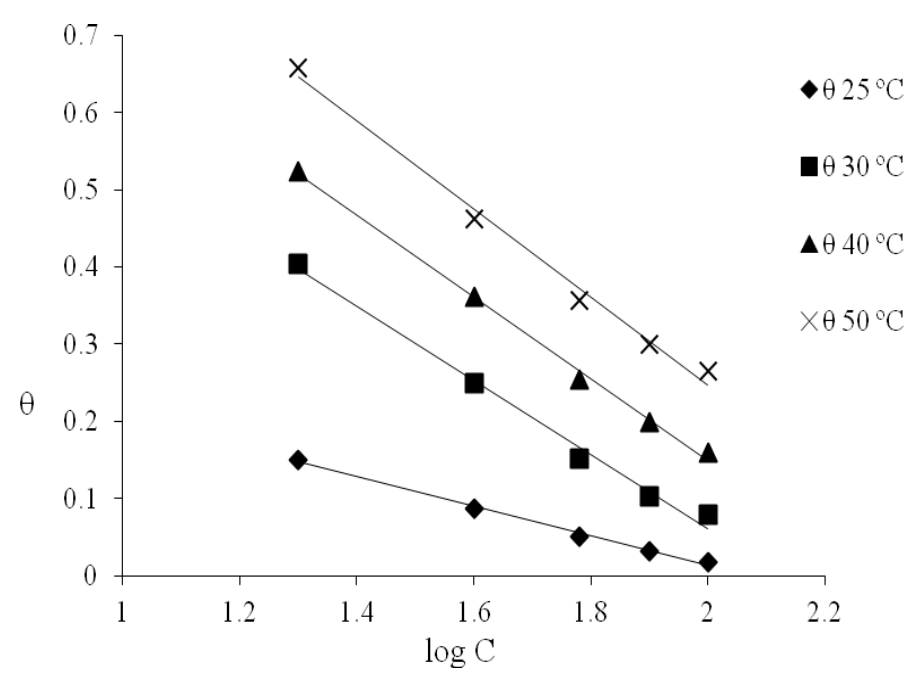

Figure 7. Temkin adsorption isotherm plot as $\theta$ against $\log \mathrm{C}$ for L. varius $l$. extract at different temperatures for aluminum corrosion.

Table 3. Langmuir and Temkin adsorption parameters for the adsorption of of L. varius $l$. extract on aluminum in $1 \mathrm{M} \mathrm{NaOH}$ for $60 \mathrm{~min}$ immersion period at different temperatures.

\begin{tabular}{|c|c|c|c|c|}
\hline Isotherm & Temperature (K) & $\mathbf{L o g} \mathbf{K}$ & $\mathbf{R}^{2}$ & $\Delta \mathbf{G}_{\text {ads }}, \mathbf{~ k J m o l}^{-1}$ \\
\hline Langmuir & 298 & -0.5197 & 0.9961 & -19.78 \\
\cline { 2 - 5 } & 303 & -0.1498 & 0.9942 & -18.28 \\
\cline { 2 - 5 } & 313 & -0.0763 & 0.9960 & -17.23 \\
\cline { 2 - 5 } & 323 & -0.0224 & 0.9968 & -16.20 \\
\hline \multirow{4}{*}{ Temkin } & 298 & -1.072 & 0.9951 & -3.84 \\
\cline { 2 - 5 } & 303 & -1.129 & 0.9906 & -3.57 \\
\cline { 2 - 5 } & 313 & -1.281 & 0.9972 & -2.78 \\
\cline { 2 - 5 } & 323 & -1.432 & 0.9916 & -1.93 \\
\hline
\end{tabular}


As shown in Fig. 8, the corrosion data fit the first-order reaction rate law as expressed in Equation (11)

$$
\log [\mathrm{Wi}-\Delta \mathrm{W}]=-\mathrm{kt} / 2.303+\log \mathrm{wi}
$$

where $\mathrm{Wi}$ is the initial weight of aluminum specimen, $\Delta \mathrm{W}$ is the weight loss of aluminum specimen at time $\mathrm{t},[\mathrm{Wi}-\Delta \mathrm{W}]$ is the residual weight of aluminum coupon at time $\mathrm{t}$ and $\mathrm{k}$ is the first-order rate constant. The linear plots obtained with correlation coefficients close to 1 confirm a first-order kinetics for the corrosion of aluminum in $1 \mathrm{M} \mathrm{NaOH}$ solution in the presence and absence of Lupinus varius $l$. extract.

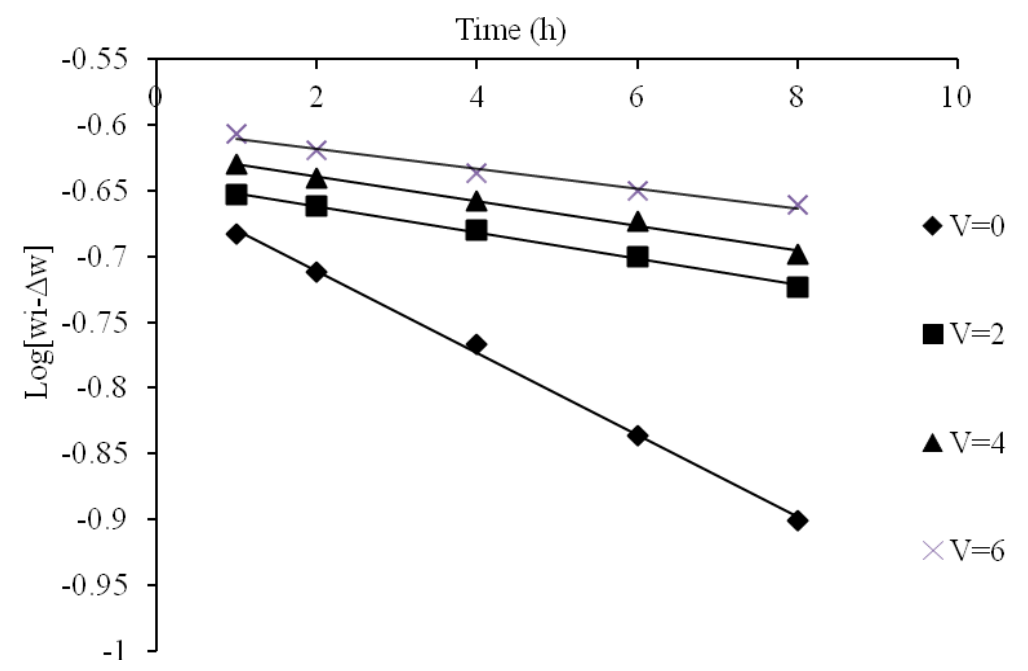

Figure 8. Plot of $\log [w i-\Delta w]$ versus time for $\mathrm{Al}$ in $1 \mathrm{M} \mathrm{NaOH}$ solution with and without $L$. varius $l$. extract at $25^{\circ} \mathrm{C}$.

\section{Conclusions}

From the experimental results obtained in the present study, the following conclusions could be drawn:

1. L. varius $l$. extract acts as inhibitor for aluminum corrosion in $\mathrm{NaOH}$ solution.

2. Inhibition efficiency increased with increase in concentration of the $L$. varius $l$. extract but decreased with increase in temperature. Phytochemical constituents in the extract play a very vital role in the inhibiting action.

3. Activation energies were higher in the presence of the exudates gum suggesting physisorption mechanism.

4. The present study provides new information on the inhibiting characteristic of a $L$. varius $l$. extract under the specified conditions. The adsorption of $L$. varius $l$. extract fits into Langmuir isotherm and Temkin isotherm models and a first-order kinetics relationship was obtained from the kinetics treatment of the data of weight loss measurements.

\section{Acknowledgment}

The authors would like to thank the Yarmouk University - faculty of graduate studies and scientific research for providing financial support. 


\section{References}

1. Abiola OK, Otaigbe JOE. Corros Sci.2008;50:242-247.

2. Yazdzad AR, Shahrabi T, Hosseini MG. Mater Chem Phys. 2008;109:199.

3. Doche ML, Rameau JJ, Durand R, Novel-Cattin F. Corros Sci. 2007;41:805.

4. Onuchukwu AI., Mater Chem Phys. 1990;24:337-341.

5. Gunasekaran SG, Chauhan LR. Electrochim Acta. 2004;49:4387.

6. Mazhar AA, Arab ST, Noor EA. Bulletin Electrochem. 2001;17:449.

7. Baumgaertner M, Kaesche H. Corros Sci. 1990;31:231.

8. El-Shafei AA, Abd El-Maksoud SA, Fouda AS. Corros Sci. 2004;46:579.

9. Muller B. Corros Sci. 2006;46:159.

10. Emeregul KC, Aksut AA. Corros Sci. 2000;42:2051.

11. Zhang J, Klasky M, Letellier BC. J Nuclear Mater. 2009;384:175.

12. Umoren SA, Obot IB, Ebenso EE, Okafor PC, Ogbobe O, Oguzie EE. AntiCorros Methods Mater. 2006;53:277.

13. Umoren SA., Obot IB, Ebenso EE, Okafor PC. Port Electrochim Acta. 2008;26:267.

14. Tackholm V. Students Flora of Egypt. 2nd ed. Cairo: Cairo University Press; 1974. P. 224.

15. Wink M, Meibner C, Witte L. Phytochemistry. 1995;38:139.

16. Peterson J. Aust. J Exp Biol Med Sci. 1963;41:903.

17. Abdel-Halim OB, El-Gammal AA, Abdel-Fattah $\mathrm{H}$, Takeya $\mathrm{K}$. Phytochemistry. 1995;41:5.

18. Amitha Rani BE, Bharathi Bai J. Int J Corrosion. In press.

19. Umoren SA, Obot IB, Ebenso EE. E-J. Chem. 2008;5:355.

20. Valek L, Martinez S. Mater Lett. 2007;61:148.

21. Obot IB, Obi-Egbedi NO. Port Electrochim Acta. 2009;27:517.

22. Tarasova NS, Khachaturyan MA, Nikolaev LA. Russ J Phys Chem. 1984;58:628.

23. Sosnina NA, Mironov VF, Karaseva AN, Minzanova ST, Karlin VV, Enikeev KM, Konovalov AI, Lapin AA, Kononov AS, Takunov IP. Chem Natural Compounds. 2000;36:40.

24. Al-Qudah MA. Arab J Chem. In press.

25. Awad MI. J Appl Electrochem. 2006;36:1163. 